\title{
Health professionalism must be ensured online and offline
}

\author{
Moneeza Walji MD MPH, Matthew B. Stanbrook MD PhD
}

See also page 549 and www.cmaj.ca/lookup/doi/10.1503/cmaj.141417

$\mathrm{T}$ he public rightfully expects health professionals to honour the trust put in them and to respect privacy. When some of these professionals publicly promote the idea of using anesthetics to rape women - even in jest and make degrading, misogynistic remarks about their female colleagues, as occurred recently in a Facebook group of male dental students at Dalhousie University, ${ }^{1}$ the public is understandably outraged. It falls to the dental profession and the university to address this incident, and they are, but it would be naive to believe that such attitudes and behaviours are unique to dental students. This incident is a sentinel event that should prompt the medical profession to reflect on whether we are safeguarding our professionalism adequately.

Medical trainees are not exempt from sexual harassment and other serious professional lapses. Sixty percent of US medical schools surveyed in 2009 reported at least one incident of a student posting unprofessional content online. ${ }^{2}$ More troubling, national surveys of US medical graduates between 2000 and 2011 found that $25 \%$ reported mistreatment that included sexist names or remarks and that $13 \%$ had experienced unwanted sexual advances, some involving medical colleagues or supervisors. ${ }^{3}$

There exists a wider societal problem of gender-based violence and victimization. Statistics Canada documented 21300 reported assaults in Canada in 2013. However, an estimated $88 \%$ of sexual assaults go unreported. ${ }^{4}$ But could medicine, with its culture of exceptionalism and the privilege to transgress boundaries forbidden to others, render trainees uniquely vulnerable to unprofessionalism?

In medical school, trainees are thrust into anatomy classes and made to disturb the sanctity of a dead body. Physicians are taught to ask probing questions about patients' personal, sexual and drug histories without hesitation and to conduct examinations that invade the most private of our patients' physical spaces. Medical training repeatedly conveys implicit or explicit messages that physicians are at the extreme of intuition and intelligence and are heroic in their endurance of tremendous pressures in medical education and medical practice. Being in a position of power among vulnerable populations, having access to medications that can harm and being entrusted to make recommendations in the best interest of patients all require maturity. The risk of transgression is high, with serious consequences.

Social media threatens professional behaviour through its deceptive blurring of the boundary between public and private. Many of the Dalhousie dental students who posted and "liked" comments on their Facebook group were probably aware that what was being said was wrong and disrespectful. Shrouded in the relative anonymity of the Internet and a closed group, however, they may have felt immune to the criticism they would have faced if these comments had been made in public. But online comments are not private - they have public consequences. Online behaviour must mirror public behaviour.

Professionalism is not innate. It is a social phenomenon that is instilled through appropriate social and educational environments. Medical schools have become proficient at creating such environments in clinical and classroom settings, but not yet in the realm of social media. Medical educators must begin modelling professionalism online the way they currently do in person. They will likely do so only when medical curricula explicitly require use of social media as a component of teaching.

The Committee on Accreditation of Canadian Medical Schools states that a medical school should ensure "the learning environment of its medical education program is conducive to the ongoing development of explicit and appropriate professional behaviors." 5 Guidelines on professionalism and physician use of social media exist. The College of Physicians and Surgeons of Ontario, for example, presents nine recommendations, the first of which stresses that all information online should be treated as public. ${ }^{6}$ Medical schools have begun to enact professionalism policies that include social media.

These policies are a good start, but may not be enough. Dalhousie is conducting a review of the environment and culture in which its dental students learn, a process in which both perpetrators and victims of the Facebook incident have collaborated positively. Medical schools should begin doing the same to identify their own vulnerabilities proactively, rather than waiting for a similar incident with similar public embarrassment.

\section{References}

1. Dalhousie University probes misogynistic student 'Gentlemen's Club.' CBC News 2014 Dec. 15. Available: www.cbc.ca/news/canada/nova-scotia/dalhousie-university -probes-misogynistic-student-gentlemen-s-club-1.2873918 (accessed 2015 Mar. 16).

2. Chretien K, Greysen SR, Chretien J, et al. Online posting of unprofessional content by medical students. JAMA 2009;302:1309-15.

3. Mavis B, Sousa A, Lipscomb W, et al. Learning about medical student mistreatment from responses to the Medical School graduation questionnaire. Acad Med 2014;89:705-11.

4. Boyce J, Cotter A, Perreault S. Police-reported crime statistics in Canada, 2013 Ottawa: Statistics Canada; 2014. Available: www.statcan.gc.ca/pub/85-002-x/2014001 /article/14040-eng.htm (accessed 2015 Mar. 16).

5. CACMS standards and elements: standards for accreditation of medical education programs leading to the MD degree. Ottawa: Committee on Accreditation of Canadian Medical Schools; 2014. Available: www.afmc.ca/pdf/CACMS_Standards_and_ Elements_June_2014_Effective_July12015.pdf (accessed 2015 Mar. 16).

6. Social media - appropriate use by physicians. Toronto: College of Physicians and Surgeons of Ontario. Available: www.cpso.on.ca/policies-publications/positions -initiatives/social-media-appropriate-use-by-physicians\#toc3 (accessed 2015 Mar. 16).

Competing interests: See www.cmaj.ca/site/misc/cmaj_staff.xhtml

Affiliations: Editorial Fellow (Walji) and Deputy Editor (Stanbrook), CMAJ

Correspondence to: CMAJ editor, pubs@cmaj.ca

CMAJ 2015. DOI:10.1503/cmaj.150248 